\title{
IT Governance Knowledge: From Repositories to Artificial Intelligence Solutions
}

\author{
Meriyem Chergui ${ }^{1, *}$ and Aziza Chakir ${ }^{2}$ \\ ${ }^{1}$ Mathematics and Computer Sciences Department, Higher National School of Electricity and Mechanics, Hassan II University, \\ Casablanca, Morocco \\ ${ }^{2}$ Economic sciences and management Department, Faculty of Economic and Social Legal Sciences, Hassan II University, Casablanca, \\ Morocco
}

Received 17 August 2020; Accepted 15 October 2020

\begin{abstract}
Engineering sciences are nowadays interested in companies' knowledge, either individual or collective one, in order to implement processing and management systems allowing better decisions as well as replacing humans with intelligent agents for technical and business reasons. Knowledge management $(\mathrm{KM})$ is an important pillar to achieve organization best performance by deploying technics and know-how of brilliant and competent profile. It crosses several components namely: strategy processes, information systems and decision systems. IT Governance is the knowledge allowing the strategic alignment of IT with business so that the maximum value of the company is achieved by the development and effective control of information, responsibility, performance and risk management. This knowledge is mainly capitalized in good practice guidelines written by experts in the field. They make them available to companies and auditors for certification or performance improvement. However, the use of this knowledge in the right way is both expensive and complicated. This article addresses the issues related to the design and implementation of an intelligent knowledge management system for IT governance within the company normative and technical expectations.
\end{abstract}

Keywords: IT Governance, knowledge management, artificial intelligence, information system, IT Governance frameworks.

\section{Introduction}

Company is a volatile and a highly competitive business environment, which makes it difficult to have the accurate information at the right time. Digitization has proven its worth in providing useful information at the requested time and place.

The value of information has also evolved. It has become a key heritage that helps the company to become more competitive. Now considered as a privilege capital, it must be managed such as a critical resource and showcase. Nowadays information systems are increasingly complex, leading to data fluctuation, the organization in this case involves the information system governance discipline to align their strategic objectives and technology to create value.

When we talk about information system governance, we usually think of guidelines and best practices. Nevertheless, its implementation need experts since these repositories are in the form of knowledge in several specialized and detailed volumes. Reading documents is never enough, neither inviting experts. A Company IT Governance background is strongly requested to insure strategic alignment, in addition to business stakeholders and top management involvement. All the more, it is many years' knowledge and experience to achieve a maturity level enabling effective value creation from information technologies. In fact, Firas M in [1] found that the capabilities of intelligent enterprise systems and the

*E-mail address: chergui.meriyem@gmail.com

ISSN: $1791-2377$ @ 2020 School of Science, IHU. All rights reserved.

doi:10.25103/jestr.135.09 capabilities of knowledge organization have a positive dynamic influence on IT governance activities and to do it, he suggested that company needs to put more emphasis on HR expertise. Attia in [2] promotes organizational learning by treating its relationship with Knowledge Management for the organizational knowledge use and emphasizes the importance of promoting good practices that help organizational learning.

Syaiful Ali in [3] presented an empirical study offering an analysis of dimensions that help to explain knowledge of IT governance. Using absorption capacity, this study shows that to reach higher levels of knowledge absorption capacity in IT governance, companies must focus on four dimensions: prior relevant knowledge, effective communication network, appropriate communication climate and effective knowledge analysis. Adriano Olímpio in [4] presents an explanatory model of the effects of IT governance mechanisms on the IT and organizational performance of public organizations, his results indicate that IT performance is positively correlated with organizational performance. As for Mojtabaei [5], he identifies the impact of IT governance and IT capabilities on the strategic alignment between business and IT, as well as the extent of their influence, with regard to IT resource management, performance measurement, knowledge sharing and IT architecture and infrastructure. According to the results, of his study, knowledge sharing in the area of IT governance positively influences business and IT alignment as well as performance measurement. Also, Borja in [6] examine the relationship between effective IT governance, relevant IT governance knowledge and their influence on innovation products and processes. This study uses structural 
equation modeling to assess 215 valid surveys. It revealed that IT governance has a positive and significant influence on products and innovation processes. Relevant IT governance knowledge positively influences IT governance implementation when the IT governance experience is high, but when the IT governance experience is low, its effect is perceived as negative on the product and the innovation process.

To sum up, IT governance knowledge is as important as technical one in order to create value and align digital aspects to business needs. It is correlated to many decisive parameters such as product life cycle, organizational performance and communication network. However, all the research works presented bellow studied knowledge management impact in ITG field and none of them propose an engineering solution to implement it. In fact, the problem we are dealing with is how to manage IT Governance knowledge in an effective way to make it available to both stakeholders and digital solutions replacing human actors. In this paper, we use a systematic literature review to propose a knowledge management model for IT governance based on Mask method and processes planning expert system.

This article is structured as follows: after the introduction in the first section, the second section presents the basics of IT governance and focus on the process oriented aspect of repositories.

In the third section, we present KM state of art, we compare approaches, and we focus on process planning in knowledge management after presenting related works. In the fourth section, we propose an intelligent architecture of IT governance knowledge management system adapted to the digital enterprise, we discuss the solution in the fifth section. Finally, we end with a conclusion and perspectives of this research work.

\section{IT Governance basics}

\subsection{IT Governance perimeter}

Governance is a concept that can be used in many contexts [7]. There are different types of governance: "Corporate" governance and "Business" governance to balance between compliance and performance and IT governance to manage the processes enabling the business to make good use of information technology. These three types of governance are interrelated. In fact, being a subset of corporate governance, IT governance is the discipline that allows decisions to be made around IT investments: How are decisions made? who makes them, who is held responsible for their implementation? and how the results of decisions are measured and monitored?

IT governance has become one of the major priorities of companies in the digital age we are living in. It is based on five pillars, namely: Strategic alignment, value creation, risk management, resource management and performance measurement.

IT governance operational scope is a tool that promotes good IT and information decision making for better efficiency. All the more, it allows roles clarification of different stakeholders for better synergy. According to this discipline, the digital tool is no longer a matter of IT department but the whole company's one, as long as business processes are increasingly linked to the Information System. For example, with the current environment of Covid19, and with the co-funding of employees, the contribution of the Information System(IS) in business is critical. Indeed, an IS has more than ever the main mission of information technologies deployment for the company's activities service and for compliance with its business and its needs. To verify this alignment of the IS with business lines requirements and company strategy, it is necessary to have recourse to IT Governance which maps out how digital solutions are managed and controlled to achieve performance and reduce costs and risks. It allows to answer relevant questions such as:

- What relationships must exist between top Management and IT department /Information office?

- How are the roles distributed between IS users?

- What are the key processes Information office should integrate?

- How to ensure the effective use of IS?

- How to increase the sustainability of the IS?

\subsection{Frameworks and best practices}

There are several IT governance standards. each standard affects a component of governance ranging from the strategic level to treatments and services. A recurring problem of IT Governance that has been tackled in a previous work [8] is to make these repositories coexist for better results, since they present a complementarity. We present the main repositories and standards from several IT Governance points of view, namely strategy, service management, project management and information security.

There are several major families of standards per area we will present for:

- strategic benchmarks: COBIT;

- processing standards: ITIL, ISO27001, and ISO27002;

\subsubsection{Cobit}

COBIT (Control Objectives for Business Information and Related Technology), published in 1996 by ISACA (The Information System Audit and Control Association) is an IT Governance repository which initially applies the COSO directives to IT objectives. In 2000, the third version of COBIT was published as an IT management and audit guide. When the SOX law appeared, COBIT got aligned respecting the compliance aspect. After that, Cobit 4 was released in December 2005, then COBIT 4.1 in 2007 where internal control was added. The 4.1 version breaks down any computer system into 34 processes divided into four functional areas:

- Planning and organization with 10 processes.

- Acquisition and implementation with 7 processes.

- Service and support with 13 processes.

- Monitoring with 4 processes.

Each process deploys one or many IT resources (applications, information, infrastructure and people), provides information intended to meet business needs expressed in the form of criteria and concerns one of the IT Governance pillars. We have carried out several research works for the digitization of this version in a smart way [9$10]$.

In 2012, Cobit 5 was released. it integrated Val IT and Risk IT into the repository to maintain quality information that supports business decisions and strategic objectives. Cobit 5 allows, in addition to the advantages of previous versions, keeping IT risks at an acceptable level, optimizing the costs of services and IT and supporting compliance with laws. We proposed a business driven architecture which 
implements Cobit 5 in [9].

COBIT 5 is made of 5 principles:

- Respond to the needs of the parties concerned

- Cover the business from start to finish.

- Application of a single integrated framework.

- Allow a holistic approach.

- Separate governance from management.

In November 2018, COBIT 2019 has unifying and complementary vision with most of the standards that we will present as we will show later.

\subsubsection{ITIL}

ITIL v1 was a study launched by the British government in 1990 to define best practices for IT service management.

ITIL v2 was published in 2004, with 9 books highlighting the link between technology and business. He proposed the processes necessary to guide the management of IT services.

In 2007, ITIL V3 was released. Based on five works of good practice, it proposed additions by field of activity, as well as generic models (process maps, etc.). We published a research work about an IT Governance decision system based on ITIL v3 in [10].

The latest version is ITIL V4. its strong point is the integration of new agile practices and DEVOPS. It went from 26 processes in 5 categories, to 34 practices, in 3 themes: 14 in "General management practices", 17 in "Service management practices" and 3 in "Technical management practices". ITIL v4 introduces new concepts and advances existing knowledge such as the ITIL Service Value System (SVS) and the four-dimensional model.

\subsubsection{ISO27001}

ISO 27001 is a standard that implements an information security management system (ISMS). It was released in 2005 to "provide a business operating, monitoring and review model for maintaining an information security management system". It uses a risk management approach and defines a six-part planning process:

- Define a security policy.

- Define the scope of WSIS.

- Perform a risk assessment.

- Manage the risks identified.

- Select the objectives and controls to be implemented.

- Prepare a declaration of applicability.

It provides a checklist to be taken into account in the practical support code. It has documentation on management responsibilities, internal audit, continuous improvement and corrective and preventive measures. And like the other standards, it requires cooperation between all the participating parties. Our team also published a research work about an IT Governance processing system based on ISO27001 in [11]. The latest version is ISO27001 2013 with corrections in 2014 and 2015. It focuses on information technology, security techniques and information security management systems requirement.

\subsubsection{ISO27002}

The ISO27002 standard was first published in 2005. It describes a set of information security control objectives for confidentiality, integrity and availability.

Securing information according to ISO270002 goes through four essential phases.

- Scope to protect (list of sensitive goods).

- Nature of threats.

- Impact on the information system.

- Protective measures to be implemented

The latest version is ISO 27002 2013. It is an organizational standard and good practice for information security with regard to the selection, implementation and management of information in relation to environmental security measures and organizational. It is intended for organizations wishing to select the measures for implementing an information security management system (ISMS) according to ISO / IEC 27001; implement widely recognized information security measures; and develop their own information security management guidelines. This version has two fixes 2014 and 2015. Our team published a research work about an IT Governance processing system based on ISO27002 as well in [12].

\subsection{Process driven aspects of IT Governance Frameworks} An IT process is a structured set of activities triggered by a specific event to generate measurable results specific to a client and to a stakeholder [14].

In terms of cost, the process-driven aspect in almost all of IT governance frameworks is not random, it is rather the pivotal element for transforming incoming elements into outgoing elements within the organization. In addition, the IT process can be measured in terms of effectiveness and efficiency while detailing the activities to be implemented, responsibilities and controls. At this level, each repository focuses on one or more concepts which it finds more priority to define and the key concept is the process.

We are currently talking about process driven management as a management way that allows the understanding and satisfaction of requirements. Evaluation in terms of added value and measurement of performance and effectiveness is also possible by this type of management according to frequency and objective indicators.

This promotes communication between the different representatives and facilitates the choice of directions to be taken by Top Management [15].

The notion of process in general, of IT process in particular is therefore dynamic and programmable with inputs and outputs from which comes the idea of IT governance best practices automatic implementation through process planning. In this work, we will focus on process planning from Knowledge management point of view.

\subsection{IT Governance knowledge}

Companies that seek growth performance through information technologies have mainly established these repositories in a classical way: IT Governance internal or external expert implements the chosen repository according to the company specificities. He proposes the most related IT processes to top management and they discuss with stakeholders their execution. These steps mix two kind of knowledge: tacit and explicit. The explicit is the knowledge collected directly from repositories rich text, written by international experts with 30 or 40 years of experience in IT Governance domain. These texts are often misunderstood or underused. The tacit is the know how internal or external expert of a given company deploys to create value from digital solutions. It is also top management and stakeholders' contributions to achieve a maturity level. 
Otherwise, the concept of organizational memory has emerged in last years as a valuation basis by storing advances and business entries [16]. With this memory, the company can ensure knowledge transfer, achieve productivity gains and innovate in business processes. Consequently, IT governance could be a key part of the organizational memory for a digital enterprise to avoid capitalization and continuity problems in the domain such as experts' departure, top management priority changing and environmental contingencies. In the next section, we will present, the basics of Knowledge Management in order to explain the proposed solution.

\section{Knowledge Management}

\subsection{Basics}

Knowledge Management (KM) is an approach whereby the company generates wealth from its knowledge or intellectual capital. Knowledge modeling is done according to three types of approach: bottom-up, top-down and mixed. As for processes and goals, KM has many definitions according to many points of view [17]:

- functional definition: "Managing the life cycle of knowledge from the emergence of an idea: formalization, validation, dissemination, reuse and promotion."

- operational definition: "Combining knowledge and know-how in processes, products, and organizations to create value."

- economic definition: " Enhancing the intellectual capital of the firm."

There are two fundamental categories of knowledge "tacit" and "explicit" knowledge. Tacit knowledge is in people's minds and impossible or difficult to materialize. Most of the knowledge is tacit. Some knowledge is integrated into business processes, according to a continuous improvement approach for the company. Explicit knowledge takes the form of words, sentences, documents, organized data, computer programs or others. One of the major problems of $\mathrm{KM}$ is to transform tacit knowledge into explicit or to implement explicit knowledge into easily exploitable tools.

What is a knowledge? How can we model it? Knowledge is a human capacity acquired over time, which makes it possible to link information by giving it meaning beyond data.

What about KM systems? Knowledge Management Systems (KMS) are digital applications supporting the various KM processes. They involve lesson databases, directories and networks to put organizational participants in contact with recognized experts in a specific field.

KMS can be less automated than an IS, in that it may require human activity in its operation. While information systems generally require humans to make choices in the design phase and then operate automatically. KMS sometimes involves human participation in the exploitation phase. In the literature [18] several KMS issues have been raised namely

- How to provide a strategic advantage via KM?

- How to manage knowledge and provide $\mathrm{KM}$ support?

- How to update knowledge?

- How to involve individuals for the enrichment of a KMS?
- How to choose useful knowledge?

- How to assess and optimize the cost of KMS?

- How to design and develop a KMS?

- How to ensure knowledge security?

Since IT and management are the two disciplinary fields of knowledge management development, we will show in this paper, how to design and develop an IT Governance KMS by choosing useful knowledge and the right technology in order to provide a strategic advantage.

\subsection{KM Approaches comparison}

In literature, knowledge had many life cycle according to different point of view [19], namely Wiig (1993), Meyer et Zack (1996), Bukowitz et Williams (2000), McElroy (2003), Dieng (2005) and Grundstein (2009). The main steps are: capture, coding, evaluation, dissemination, sharing, contextualization, acquisition, application and update.

In addition, several methods and techniques are used for knowledge modeling. These methods can be grouped into many types of approach: bottom-up approach, top-down approach, mixed approach, cartographic approach and editorial method.

Top-down methods are model driven: The development of knowledge models in this approach consists in finding preexisting generic models (in libraries, for example) and adapting them to the domain and the application concerned. Example: MASK and CommonKADS. In the other side, the bottom-up approach is data-driven, it is based on a step of elicitation of expert knowledge (interviews, document analysis, task analysis, etc.) followed by a conceptualization step. Example: MIKE and KOD.As for, the mixed approach makes it possible to build knowledge models by combining steps from the two previous approaches [20]. As for cartographic model, it is the set of techniques and tools used to analyze and visualize areas of knowledge, the relationships between these areas in the context of certain specificities of the professions. Indeed, knowledge maps are designed by conveying certain attributes of tacit or explicit knowledge in a graphical form more understandable by experts from two points of view: process and domain.

One word about editorial methods. They are methodologies designed to save the knowledge and expertise acquired in the documentary memory for a good system of structuring descriptive knowledge

Knowledge Management as a set of models or methodologies able to implement information processing and communication tools. It aims to structure, enhance and allow access by the entire organization to the knowledge that has been developed and which have been or are still being put into practice within it. In [21] authors propose a comparative analysis of Knowledge Management methods for a managerial approach according to their methodology, their goal, knowledge level explicitation, knowledge formalization and tools. They deal with top down, editorial and cartographic approaches. We add to their work, bottom up and mixt approach to have a clear vision as shown in the table 1 .

We note that the top down approach is distinguished by its knowledge engineering vison. It allows maximum explicitation of knowledge and its easy integration in the information system. It is visible when we compare it to other approaches namely bottom top, characterized mainly by documents and analysis in knowledge inventory level and a medium explicitation level with partial formalization. 
Table 1. KM methods comparison

\begin{tabular}{|c|c|c|c|c|c|}
\hline KM Approach & Top-down & Bottom- top & Mixt & Editorial & Cartographic \\
\hline Example type & MASK & KOD & ACCACIA & REX & GINGO \\
\hline $\begin{array}{l}\text { Knowledge } \\
\text { inventory }\end{array}$ & interviews & $\begin{array}{l}\text { interviews, } \\
\text { document } \\
\text { analysis, task } \\
\text { analysis, etc.) } \\
\text { followed by a } \\
\text { conceptualization } \\
\text { step }\end{array}$ & $\begin{array}{l}\text { gather knowledge } \\
\text { on the domain and } \\
\text { the problem- } \\
\text { solving task fro } \\
\text { Data. }\end{array}$ & $\begin{array}{l}\text { interviews then } \\
\text { Declarations } \\
\text { Spontaneous } \\
\text { experiences }\end{array}$ & $\begin{array}{l}\mathrm{CV} \text { interviews or } \\
\text { analysis }\end{array}$ \\
\hline Objective & $\begin{array}{l}\text { introducing } \\
\text { knowledge into the } \\
\text { information } \\
\text { system }\end{array}$ & $\begin{array}{l}\text { knowledge } \\
\text { extraction and } \\
\text { modeling }\end{array}$ & $\begin{array}{l}\text { operationalization } \\
\text { of a conceptual } \\
\text { model }\end{array}$ & $\begin{array}{l}\text { creating database } \\
\text { or documentaries } \\
\text { from past } \\
\text { experiences }\end{array}$ & $\begin{array}{l}\text { establish a } \\
\text { knowledge map } \\
\text { to allow their } \\
\text { management } \\
\text { (transfers, } \\
\text { acquisitions, and } \\
\text { protection) }\end{array}$ \\
\hline $\begin{array}{l}\text { Knowledge } \\
\text { Level } \\
\text { explicitation }\end{array}$ & Strong & Medium & Medium & Medium & None \\
\hline $\begin{array}{l}\text { Knowledge } \\
\text { formalization }\end{array}$ & Total & Partial & Partial & Partial & Absence \\
\hline Tools & $\begin{array}{l}\text { Predefined } \\
\text { knowledge models }\end{array}$ & $\begin{array}{l}\text { Practical model, } \\
\text { cognitive model } \\
\text { and digital model. }\end{array}$ & $\begin{array}{l}\text { choose a diagram } \\
\text { of the adequate } \\
\text { conceptual model, } \\
\text { instantiate it and } \\
\text { operationalize it }\end{array}$ & $\begin{array}{l}\text { predefined } \\
\text { teaching sheets }\end{array}$ & knowledge tree \\
\hline $\begin{array}{l}\text { Similar } \\
\text { methods }\end{array}$ & CommonKADS & MIKE & $\begin{array}{l}\text { Duribreux- } \\
\text { Cocquebert/ }\end{array}$ & MEREX, & $\begin{array}{l}\text { GAMETH, } \\
\text { MASK II }\end{array}$ \\
\hline
\end{tabular}

As for editorial and cartographic approaches, it is impossible to formalize and implement knowledge for an easy final use but only for a knowledge tree or knowledge map.

Otherwise, among top down methods, Authors compared MASK and CommonKADS in [22]. They deduce that MASK manages knowledge from several points of view compared to CommonKads, namely: activity, task, phenomenon, concept and Evolution. In addition, Mask has also a cartographical vision (Mask II) to allow their management (transfers, acquisitions, and protection) among experts using knowledge trees.

According to this comparison, we choose Mask Method in this article to model IT Governance Knowledge in an intelligent way.

\subsection{MASK Knowledge Management Method}

MASK method is based on a general knowledge model systemically speaking. This general model is based in a first level on the semiotic triangle whose three axes correspond to the following points of view:

- Syntactic: it concerns the form of information.

- Semantics: it concerns the meaning of information.

- Pragmatic: it concerns the context in which the meaning of the information takes place.

In the second level, every point of view of the semiotic triangle is detailed on three points according to the systemic triangle as shown in figure 1[23]:

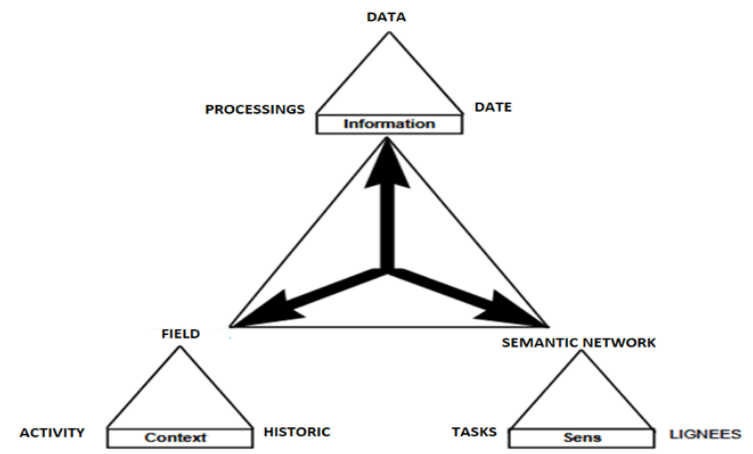

Fig 1. Knowledge Macroscope Axiom

Which theoretically gives 9 points of view and in practice 7 points of view of knowledge modeling: reference model, phenomenon model, task model, activity model, concept model, history model and lineage model. Indeed, this vision allows the expert, the knowledge engineer and the end users to better identify, capitalize, update and exploit the knowledge. This gives the opportunity to catch up in the event of non-understanding and also to focus on an aspect if we need knowledge finer level of granularity.

A knowledge in Mask Method is presented as following:

$\operatorname{Val}(k)=F\left(\operatorname{Val}_{I}(k), \operatorname{Val}_{S}(k), \operatorname{Val}_{C}(k)\right)$

Where $\mathrm{k}$ is a knowledge, I as information space, $\mathrm{S}$ as sense space and $\mathrm{C}$ as context space.

In the fifth section we will use this function to model IT governance knowledge managed in the proposed architecture. 


\section{Methodology}

In this article we applied a Systematic Literature Review based on articles from 2016 to 2020 about ITG knowledge management system. The review aimed to identify and summarize the main contributions published regarding digital ITG knowledge management. To look for these contribution three research engine were selected: Google Scholar, Taylor and Francis; and Scopus Database. The request was: "IT Governance knowledge management platform" or "IT Governance knowledge management system" or "IT Governance knowledge". None of them gives a digital platform to manage ITG knowledge or an engineering solution for the above problematic. But we find 3 categories of publications while choosing inclusive and exclusive criteria: "IT Governance" AND "Knowledge Management". To have more results we didn't specify quality assessment criteria for publication journals: knowledge governance issues: namely in finance data, incidents or HR...etc.; KM platforms governance and Knowledge management governance problems.

Table 2. KM and IT Governance publications filtration

\begin{tabular}{|c|c|c|}
\hline Publication subjects & $\begin{array}{l}\text { Assessment } \\
\text { criteria }\end{array}$ & $\begin{array}{l}\text { Results } \\
\text { count }\end{array}$ \\
\hline Knowledge governance issues & $\begin{array}{l}\text { Search } \\
\text { Category and } \\
\text { keywords } \\
\text { using the } \\
\text { filter "", }\end{array}$ & 563.000 \\
\hline KM platforms governance & $\begin{array}{l}\text { Title }= \\
\text { Search terms }\end{array}$ & 35.800 \\
\hline $\begin{array}{l}\text { Knowledge management } \\
\text { governance problems. }\end{array}$ & $\begin{array}{l}\text { Keywords } \\
\text { inside the } \\
\text { abstract }\end{array}$ & 346.000 \\
\hline
\end{tabular}

Table 2 shows the obtained results of the 3 publications subjects with a specific assessment criterion for each lot of items. The choice of the assessment criteria depends on the proximity to the problematic of IT Governance knowledge management. Many configurations were tested before their affectation. The main conclusions authors get from collected articles selected for this literature review and divided according to the subjects in table 2 are:

- Capitalizing knowledge of value creation activities is essential for the company but represents many challenges.

- The effectiveness of a system in integrating knowledge between ecosystem participants will set it apart from its competitors, it is therefore necessary to study the management of knowledge related to development beyond the borders of the company.

- By managing resources, the information system must provide knowledge at the right range and allow the scalability of knowledge resources.

These conclusions are taken in consideration for the proposed model in the next section.

\section{Proposed architecture}

To solve the IT Governance knowledge management problem in its organizational dimension, we propose a distributed architecture with intelligent tacit and explicit knowledge management system for the governance of information and communications technologies in a digital enterprise.

Figure 2 presents a first version of the knowledge management system architecture for IT governance. It is a macroscopic viewpoint illustrating different layer to capitalize IT Governance knowledge from both repositories, experts and knowledge daily users (IT managers, top management and key stakeholders).

This architecture has mainly three intelligent agents to serve potential knowledge users. these agents interacting with each other are related to a knowledge base for managing requests. Every agent is responsible for a specific category of requests, since a user either looks for a knowledge definition (concept level), create a knowledge (in the same way update and delete) or looking for knowledge use via specific request (task/activity level).

Knowledge search agent: It is the entity responsible to seek knowledge of all kinds in the memory of the company according to the request of users in a hierarchical glossary in conjunction with the essential documents. It is connected to incremental concept model linking organization memory entities with different IT Governance concepts.

Knowledge creation agent: is the entity responsible for creating new knowledge from experienced users in connection with the best IT strategy of the Information System and business features. In the same way, experts are able to update the knowledge they create and to delete outdated ones.

Knowledge use agent: is the entity responsible for the operation of knowledge according to user request as explicit process model. It affords necessary and sufficient information for its effective implementation. This agent gives the user the detailed activity with convenient task model.

The three agents are cognitive having a learning system linked to a knowledge base which is fed mainly from the three layers.

Organizational decision Layer: able to update internal guidelines, IT processes documentations and digital strategy (tacit or explicit) with practical experiences (organizational knowledge). Coming mainly from IT managers and Information system stakeholders (as daily/regular users of this knowledge able to evaluate its efficiency and to give digital-business recommendations).

Knowledge Capitalization layer: it is the driving layer of the architecture. A knowledge manager entity takes the raw input, applied an adequate knowledge engineering model and stores the results into a storage space made available. This step is the main critical in the system since it matches tacit and explicit knowledge from IT Governance repositories and from human experts. The establishment of a search engine for internal documents and access to its databases is also guaranteed by the system.

Performance management layer: Connected to the capitalization layer storage space and passes through three performance management levels namely measurement, evaluation and modification, before transferring the knowledge to the main knowledge base available to end users. And this through intelligent entities with machine learning algorithms. Performance management is essential in a knowledge management system since knowledge is mainly tacit as part of a continuous memorization process for 
feedback. This is to favor the structuring of information bases, made up of past experiences in addition to modeling existing knowledge.

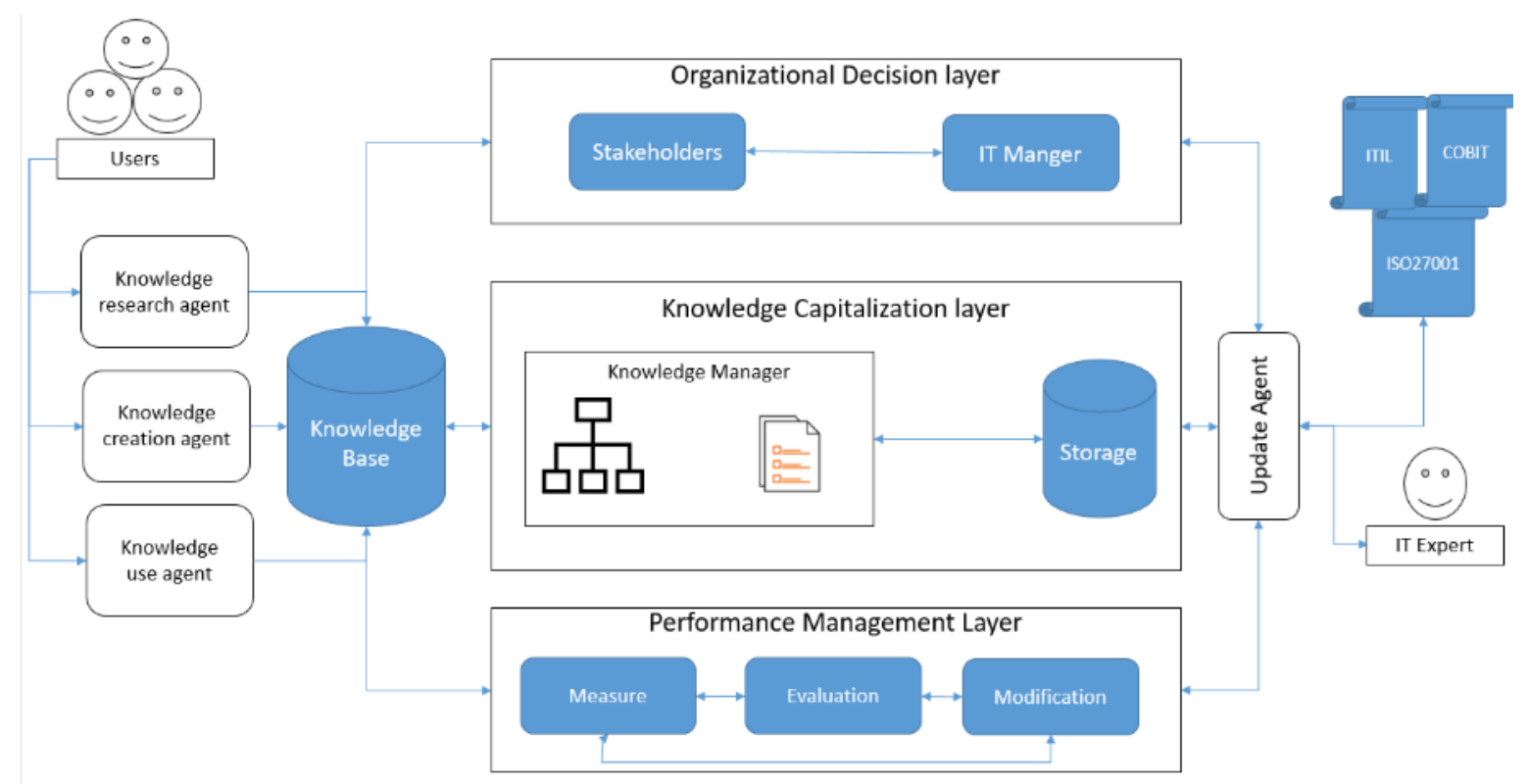

Fig. 2. The proposed architecture system

Update agent: An agent capable of updating IT Governance repositories for human experts, given the ongoing changes in different IT governance levels. And this according to the communication model in figure 3 . In fact, for every new IT Governance repository, or IT Governance Expert report/document, the update agent launch to main processes: the first one is a classical text mining task where concepts and relations are raised. The second level, after duplicates removal, an IT Governance glossary is created where every concepts is linked to documents pages and parts, according to their content tables. This level is primordial for the capitalization level, in order to create activities and tasks model and to link them to concepts. The duplication level uses a fuzzy matching algorithm to regroup concepts with their synonyms and nearer meanings in order to simplify the glossary and to manage IT Governance jargon efficiently.

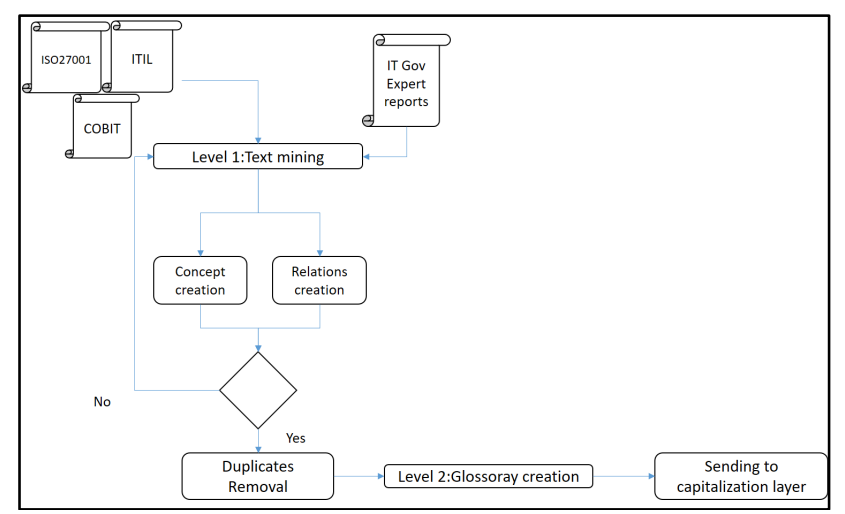

Fig 3. Update agent communication model

The proposed solution allows the clarification of IT Governance knowledge on an information support based on predefined models while ensuring knowledge capitalization, acquisition, sharing and communication. It also allows through the use of MASK the study of IT Governance knowledge according to the six graphic models corresponding to the Macroscope of figure 1. Among the strengths of the system we can list the capitalization of the knowledge of internal and external IT Governance experts, IT Strategy information corpus Structuring, knowledge integration into the company's business processes and IT Governances knowledge dissemination. Let's explain the four phases of knowledge management provided by the system via its three layers, namely the collection of IT Governance knowledge, design, dissemination and evolution. The system collects knowledge from the company's IT governance knowledge sources, namely repositories or experts. These are mainly knowledge holders: IT managers, specialists, or reference documents. It also allows interviews, actions of mobilization, cohesion and consensus through its interface for creating and updating knowledge. In the knowledge capitalization layer, MASK method (figure 4) deployed in the knowledge manager allows the implementation of several knowledge engineering models corresponding initially to the activity model, the task model and the concept model. Also, the platform allows users to edit a synthesis of knowledge in the form of a knowledge book with several configurations making it possible to enhance the documentary holdings and know-how. Its dissemination, evolution and confidentiality are supported via an appropriate reporting framework.

To sum up the proposed architecture:

- address each IT governance activity,

- identifies the main processes associated with it,

- identifies who does what and with what knowledge,

- determines the targeted knowledge,

- capitalizes, extracts and formalizes knowledge and transmit it via the knowledge search interface

\section{Implementation}

In previous works [24], we proposed an IT Governance Query 
modeling as:

\section{Query $=$ Strategic objective of the company related to IT \\ Query $=($ Perspective $) U($ Action) $U$ (Target) $U$ (Detail).}

This model was used in a matchmaking expert system for IT governance. It was tested and evaluated in [25]. As for knowledge problematic and according to the state of art above, we propose additional attributes and the query is called henceforth IT Governance knowledge query (ITGK query) according to the Macroscope axiom (see figure 1) as following:

ITGK Query $=($ Actor $(\mathrm{s})) \mathrm{U}$ (Perspective) $\mathrm{U}$ (Action) $\mathrm{U}$ (Target) U (Time) U (Detail).

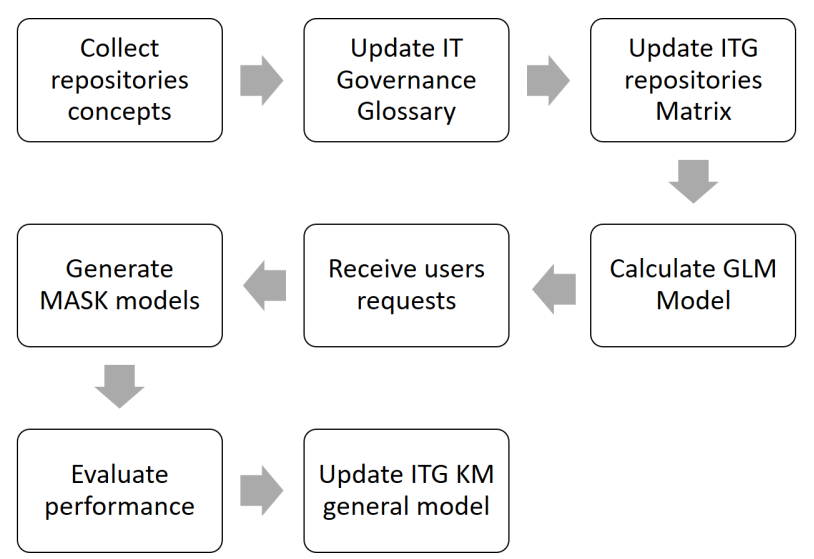

Fig 4. IT Governance Knowledge Management process

We replace perspective by context to meet axiom naming since we mean by perspective (financial, organizational, intern...). We also replace action by activity for the same reason. And later we will match every activity with a nested table of ordered tasks. So:

\section{ITGK Query = (Actors) U (Context) U (Activity) U (Target) U (Time) U (Detail).}

According to the function (1):

$\operatorname{ITGK}$ Query $=\operatorname{Val}(k)=F\left(\operatorname{Val}_{I}(k), \operatorname{Val}_{S}(k), \operatorname{Val}_{C}(k)\right)$

With:

Val $_{I}=f($ Actors, Target, Time $)$

$\mathrm{Val}_{S}=f($ Activity, Detail)

Val $_{C}=f($ Context $)$

IT Governance knowledge has three dimensions Information, Sense and Context. Every dimension has his sub dimensions as shown above So:

$$
\begin{aligned}
& \operatorname{Val}_{I}(k)=f\left(\text { Actors }_{k}, \operatorname{Target}_{k}, t\right) \\
& \operatorname{Val}_{S}(k)=f(\operatorname{Activity}(\mathrm{k}), \operatorname{Detail}(\mathrm{k})) \\
& \operatorname{Val}_{C}(k)=f(\operatorname{Context}(k))
\end{aligned}
$$

As for information dimension, its sub dimensions are actors, target and time variable we represent it with a polynomial model as following:
$\operatorname{Val}_{I}(k)=\sum_{i}^{n} a_{i} x_{i k}+\sum_{i}^{m} b_{i} y_{i k}+g\left(t_{k}\right)$

with $a_{i}$ : RACI Matrix coefficient of $i$ actor, $b_{i}:$ i target coefficient $\{0$ if not exists, 1 if exists $\}$, $\mathrm{g}(\mathrm{t})$ time function defined by IT Governance Knowledge expert.

In the same way, sense dimension has two sub dimensions: activity and detail

$\operatorname{Val}_{S}(k)=\sum_{i}^{n} \alpha_{i} x_{i k}+\sum_{i}^{m} \beta_{i} y_{i k}$

As for context dimension, it is a constant having perspectives values (financial, customer, internal, learning and growth)

$\operatorname{Val}_{c}(k)=\gamma_{k}$

$\mathrm{k}$ is an IT Governance knowledge either from repositories, from human experts or from internal IT Governance documents. The ITGK Query is a knowledge and timing function.

We simulate knowledge functions presented above with COBIT 4.1, ITIL V3 and ISO27001 as first test. To simplify the simulation ITGK query= Business Goal.

To implement this model, we follow 4 steps:

1.Creating ITG repositories matrix according to the polynomial $\mathrm{Val}(\mathrm{k})$ function above,

2. Using General Linear Model to calculate $\boldsymbol{a}_{\boldsymbol{i}}, \boldsymbol{b}_{\boldsymbol{i}}, \boldsymbol{\alpha}_{\boldsymbol{i}}, \boldsymbol{\beta}_{\boldsymbol{i}}$ 3. Predicting users ITGK queries answers

4. Updating regularly ITG repositories matrix with new frameworks.

The developed prototype is a web application in $\mathrm{J} 2 \mathrm{EE}$ technology with JPA as a framework for organizing data in applications, EJB as software components on the server side to create distributed components, to offer services with or without conservation of state between calls (EJB Session) or even to perform tasks asynchronously (EJB Message), JSF as presentation framework.

For intelligent agents' implementation Madkit 5 API is used as source libraries imported into an external library at in the development environment. For this first version of the semantic analysis we used the Apache Solr server version 5.1.1 configured with the "IT Governance Ontology" in owl format [9] and also Solr API to communicate with the platform's processing.

The screens below illustrate the first prototype of platform functionalities:

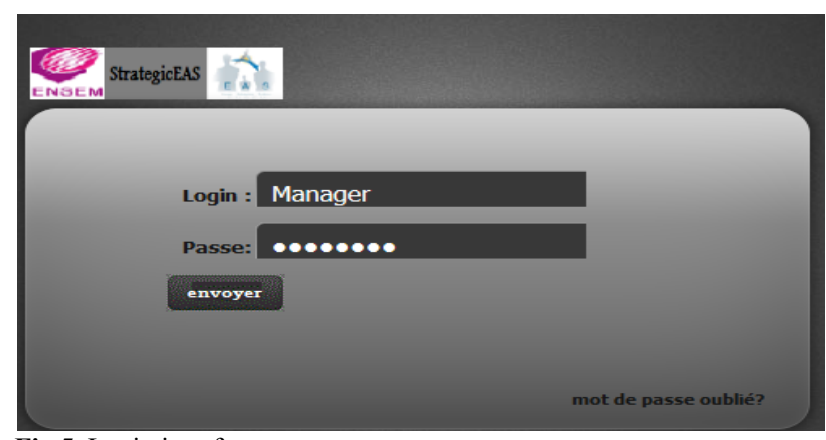

Fig 5. Login interface

The platform ensures secure authentication to both knowledge users and knowledge providers with login password. 


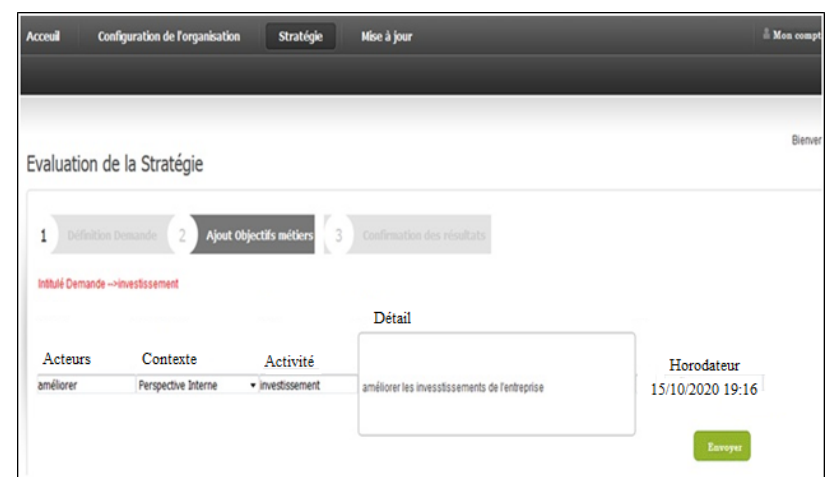

Fig 6. Knowledge search

In figure 6 a knowledge user submits a business goal and look for corresponding IT Governance knowledge from repositories and IT Strategy key documents. The request as explained before is: ITGK Query $=$ (Actors) $U$ (Context) $U$ (Activity) U (Target) U (Time) U (Detail). The user fills in the fields of the request and asks the system to evaluate it from an IT Governance knowledge management point of view

He obtains results in figure 7 . For the request he launches, he gets the activity (id=24) and tasks $(5,23,15)$ with knowledge source namely: COBIT, IT Strategy as internal document and ISO27001.

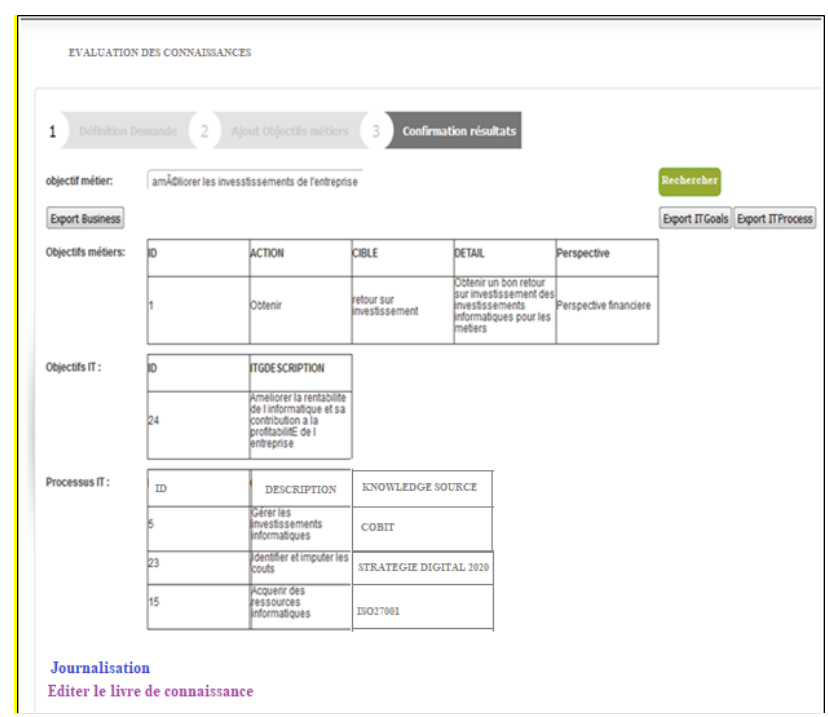

Fig. 7. Results window

\section{Conclusion and perspectives}

In this article, after an introduction about the importance of IT Governance knowledge and its related works, we gave a brief state of the art of IT Governance and Knowledge Management. Then, we presented the problem related to the intelligent and dynamic use of IT governance knowledge. We used a Systematic Literature Review as methodology to proposed an intelligent and distributed architecture for reusable, easy and up to date IT governance knowledge management system. The mathematical model of the capitalization layer was also initiated with an optimized general process and a prototype implementation with screenshots and explanations.

In future works, we will present IT Governance knowledge management modeling with detailed algorithms and results evaluation. We will also integrate this system as part of EAS IT Governance generic platform. We plan detailing different layers with their technical and technological characteristics meeting the challenges of knowledge management by exploiting the strengths of artificial intelligence.

This is an Open Access article distributed under the terms of the Creative Commons Attribution License

\section{References}

[1] Alkhaldi, F. M., Hammami, S. M., Kasem, S., Rashed, A., \& Alraja, M. N. (2017). Enterprise system as business intelligence and knowledge capabilities for enhancing applications and practices of IT governance. International Journal of Organizational and Collective Intelligence (IJOCI), 7(2), 63-77.

[2] Attia, A., \& Eldin, I. E. (2018). Organizational learning, knowledge management capability and supply chain management practices in the Saudi food industry. Journal of Knowledge Management.

[3] Ali, S., Green, P., \& Robb, A. (2013). Measuring top management's IT governance knowledge absorptive capacity. Journal of Information Systems, 27(1), 137-155.

[4] Tonelli, A.O., de Souza Bermejo, P.H., Aparecida dos Santos, P. et al. It governance in the public sector: a conceptual model. Inf Syst Front 19, 593-610 (2017). https://doi.org/10.1007/s10796-0159614-x

[5] Raymond, L., Bergeron, F., Croteau, A. M., \& Uwizeyemungu, S. (2019). Determinants and outcomes of IT governance in manufacturing SMEs: A strategic IT management perspective. International Journal of Accounting Information Systems, 35, 100422.
[6] Borja, S., Kim, K., Yoon, H., \& Hwang, J. (2018, August). IT governance effectiveness and its influence on innovation product and process. In 2018 Portland International Conference on Management of Engineering and Technology (PICMET) (pp. 1-8). IEEE.

[7] Gregory, R. W., Kaganer, E., Henfridsson, O., \& Ruch, T. J. (2018). IT Consumerization and the Transformation of IT Governance. Mis Quarterly, 42(4), 1225-1253.

[8] Chergui, M., Chakir, A., Medromi, H., \& Sayouti, A. (2016). Strategic IT governance platform based on matchmaking multiagent system and loose inter-organizational workflows. International Journal of Computer Science and Information Security, 14(5), 362.

[9] CHERGUI, M., CHAKIR, A., \& MEDROMI, H. (2019, July). Smart IT Governance, Risk and Compliance Semantic Model: Business Driven architecture. In 2019 Third World Conference on Smart Trends in Systems Security and Sustainablity (WorldS4) (pp. 297301). IEEE.

[10] Chergui, M., Chakir, A., Medromi, H., \& Radoui, M. (2016, May). A New Approach for Modeling Strategic IT Governance Workflow. 
In International Symposium on Ubiquitous Networking (pp. 285298). Springer, Singapore.

[11] Chakir, A., Chergui, M., \& Andry, J. F. (2020). A smart updater it governance platform based on artificial intelligence. risk, 8, 9 .

[12] Ghazouani, M., Medromi, H., \& Moussaid, L. (2017). Design and Implementation of a Comprehensive Information Security Risk Management Tool based on Multi-agents Systems. Int. J. Appl. Inf. Syst., 12(7), 1-8.

[13] ELHASNAOUI, S., IGUER, H., FARIS, S., \& MEDROMI, H. (2018). Multi-agent architecture for distributed IT GRC platform. International Journal of Computer Science and Information Security (IJCSIS), 16(2).

[14] Peng, J., Quan, J., Zhang, G., \& Dubinsky, A. J. (2016). Mediation effect of business process and supply chain management capabilities on the impact of IT on firm performance: Evidence from Chinese firms. International Journal of Information Management, 36(1), 8996.

[15] Hentrich, C., \& Zdun, U. (2016). Process-Driven SOA: Patterns for Aligning Business and IT. CRC Press.

[16] Cegarra-Navarro, J. G., \& Martelo-Landroguez, S. (2020). The effect of organizational memory on organizational agility. Journal of Intellectual Capital.

[17] Martins, V. W. B., Rampasso, I. S., Anholon, R., Quelhas, O. L. G., \& Leal Filho, W. (2019). Knowledge management in the context of sustainability: Literature review and opportunities for future research. Journal of cleaner production, 229, 489-500.

[18] Ouriques, R. A. B., Wnuk, K., Gorschek, T., \& Svensson, R. B. (2019). Knowledge management strategies and processes in agile software development: a systematic literature review. International journal of software engineering and knowledge engineering, 29(03), 345-380.

[19] Alexandru, V. A., Bolisani, E., Andrei, A. G., Cegarra-Navarro, J. G., Martínez, A. M., Paiola, M., ... \& Zieba, M. (2019). Knowledge management approaches of small and medium-sized firms: a cluster analysis. Kybernetes.

[20] Latilla, V. M., Frattini, F., Petruzzelli, A. M., \& Berner, M. (2018). Knowledge management, knowledge transfers and organizational performance in the arts and crafts industry: a literature review. Journal of Knowledge Management.

[21] Sensuse, D. I., \& Cahyaningsih, E. (2018). Knowledge management models: a summative review. International Journal of Information Systems in the Service Sector (IJISSS), 10(1), 71-100.

[22] Tapissier, E., Mantelet, F., \& Aoussat, A. (2018). Choosing the right tools and practices to design a knowledge management system in a SME. in ds 92: proceedings of the design 2018 15th International Design Conference (pp. 1697-1708).

[23] Unger, M., \& Polt, W. (2017). The knowledge triangle between research, education and innovation-a conceptual discussion. Форсайт, $11(2$ (eng)).

[24] Meriyem, C., Adil, S., \& Hicham, M. (2015). IT Governance ontology building process: example of developing audit ontology. International Journal of Computer Techniques, 2(1), 134141.

[25] Chergui, M., Chakir, A., Medromi, H., \& Sayouti, A. (2016). Strategic IT governance platform based on matchmaking multiagent system and loose inter-organizational workflows. International Journal of Computer Science and Information Security, 14(5), 362. 